\title{
Investigation of the Medicinal Potentials of Syzygium jambos (L.) Extract and Characterization of the Isolated Compounds
}

\author{
Majidul Haque ${ }^{1}$, Mst. Marium Begum², Moynul Hasan ${ }^{3}$, A. F. M. Towheedur Rahman ${ }^{4}$, \\ Md. Iftekhar Hussain ${ }^{5}$, Mohammad Mizanur Rahman ${ }^{5}$, Md. Hazrat Ali ${ }^{6}$, Md. Ashraful Islam ${ }^{7}$, \\ Md. Zakir Sultan ${ }^{8}$, Md. Reyad-ul- Ferdous ${ }^{4}$, Choudhury Mahmood Hasan ${ }^{1, *}$ \\ ${ }^{1}$ Department of Pharmaceutical Chemistry, Faculty of Pharmacy, University of Dhaka, Dhaka-1000, Bangladesh \\ ${ }^{2}$ Department of Pharmaceutical Technology, Faculty of Pharmacy, University of Dhaka, Dhaka-1000, Bangladesh \\ ${ }^{3}$ Department of Pharmacy, Dhaka International University, Dhaka-1213, Bangladesh \\ ${ }^{4}$ Department of Pharmaceutical Sciences, North South University, Dhaka-1229, Bangladesh \\ ${ }^{5}$ Department of Pharmacy, Primeasia University, Dhaka-1213, Bangladesh \\ ${ }^{6}$ Department of Pharmacy, International Islamic University, Chittagong-4203, Bangladesh \\ ${ }^{7}$ Department of Biomedical Imaging, Faculty of Bioscience, Abo Akademi University, Turku, Finland \\ ${ }^{8}$ Centre for Advanced Research in Sciences, University of Dhaka, Dhaka-1000, Bangladesh
}

Email address:

cmhasan@gmail.com (C. M. Hasan),rockyreyad@yahoo.com (Md. Reyad-ul-Ferdous)

\section{To cite this article:}

Majidul Haque, Mst. Marium Begum, Moynul Hasan, A. F. M. Towheedur Rahman, Md. Iftekhar Hussain, Mohammad Mizanur Rahman, Md. Hazrat Ali, Md. Ashraful Islam, Md. Zakir Sultan, Md. Reyad ul Ferdous, Choudhury Mahmood Hasan. Investigation of the Medicinal Potentials of Syzygium jambos (L.) Extract and Characterization of the Isolated Compounds. American Journal of Bio Science. Special Issue: Pharmacological and Phytochemicals Investigation. Vol. 3, No. 2-1, 2015, pp. 12-18. doi: 10.11648/j.ajbio.s.2015030201.13

\begin{abstract}
Syzygium jambos (L.) Alstone belonging to the Myrtaceae family have been investigated for isolation of their secondary metabolites and evaluation of their biological activities. A total of three compounds have been isolated. The isolated compounds were identified by extensive analysis of their high resolution 1H-NMR spectroscopic data.The dried stem barks of Syzygium jambos was extracted with methanol. The concentrated methanolic extract was then partitioned with vacuum liquid chromatography. The first investigation was conducted with the VLC fraction-6 afforded one pentacyclic triterpenes (SJ-61), VLC fraction-9 afforded a sitosterol (SJ-92) and VLC fraction-16 afforded a triterpene 3-nor-2,3-fridelan derivative (SJ-184). In the brine shrimp lethality bioassay, $\mathrm{The}^{\mathrm{LC}} \mathrm{C}_{50}$ values were found to be $6.97,18.07,64.943,247.596$ and $12.75 \mu \mathrm{g} / \mathrm{ml}$ for crude methanolic extract, carbon tetrachloride, chloroform and $n$-hexane soluble fractions of methanolic extract of Syzygium jambos respectively representing methanolic extract fraction as highly cytotoxic.
\end{abstract}

Keywords: Medicinal Plant, Extraction, Isolation, Characterization, Cytotoxicity, Biological Activity

\section{Introduction}

In the plant kingdom there is a remedy for every disease ${ }^{[1]}$ Two hundred and fifty years ago, there were few or no synthetic medicines. The plants were the main source of drugs for the world's population. Today, $75 \%$ of the world's population, the poor $3 / 4$ ths, still relies on those plants and other tools of traditional medicine ${ }^{[2]}$. Plants have provided a source of inspiration for novel drug compounds, as plant derived medicines have made large contributions to human health and well-being ${ }^{[3]}$.
The number of higher plant species (angiosperms and gymnosperms) on this planet is estimated at $250,000^{[4]}$, with a lower level at $215,000^{[5]}$ and an upper level as high as $500,000^{[6,7]}$. Of these, only about $6 \%$ have been screened for biologic activity, and a reported $15 \%$ have been evaluated phytochemically ${ }^{[8]}$. Chemical diversity of secondary plant metabolites that results from plant evolution may be equal or superior to that found in synthetic combinatorial chemical libraries. Success in natural products research is conditioned by a careful plant selection, based on various criteria such as chemotaxonomic data, ethnomedical information, field 
observations or even random collection. One main strategy in the isolation of new leads consists of the so-called bioactivity-guided isolation, in which pharmacological or biological assays are used to target the isolation of bioactive compounds $^{[9]}$.

The work described in this dissertation is an attempt to isolate and characterize the chemical constituents of medicinal plants, viz., Syzygium jambos (Fam. Myrtaceae) and to evaluate the possible cytotoxic profiles of the crude extracts

\section{Materials and Methods}

Collection and preparation of the plant (Syzygium jambos) material: Plant sample of Syzygium jambos were collected from Gazipur, Bangladesh and was identified by an expert taxonomist of Botany Department, University of Dhaka (plant reference no. is DUSH7179). The stem barks were separated, cut into small pieces, sun dried for several days followed by oven dried for 24 hours at $40^{\circ} \mathrm{C}$ to facilitate grinding and finally crushed into course powder.

Extraction and fractionation: About 200gram of powdered stem barks in methanol for two weeks with occasional shaking. The mixture was filtered, concentrated at $39^{\circ} \mathrm{C}$ to have a concentrated crude extract. 5 gram of the extract was subjected to solvent-solvent partition for investigation of the biological activities and the remaining amount was used for chemical investigation ${ }^{[10,11]}$. The concentrated methanol extract (5 g) was fractionated by modified Kupchan method $^{[12]}$ and the resultant partitionates i.e., petroleum ether, carbon tetrachloride, chloroform and aqueous soluble materials were used for different biological screenings.

\subsection{Chemical Investigation of the Purified Crude Extract of S. jambos}

The methanol extract was subjected to extensive chromatographic separation. The isolated pure compounds were then characterized by extensive spectroscopic studies like proton NMR techniques, using $\mathrm{CDCl}_{3}$ as solvent.

\subsection{Brine Shrimp Lethality Assay of the Purified Crude Extract of S. jambos}

This technique ${ }^{[13]}$ was applied for the determination of general toxic property of the plant extractives indicating bioactive materials using Artemia salina in a 1-day in vivo assay. Vincristine sulfate was used as positive control. Brine shrimp lethality bioassay ${ }^{[14]}$ is a rapid and comprehensive bioassay for the bioactive compounds of natural and synthetic origin and is considered a useful tool for preliminary assessment of toxicity.

Brine shrimp toxicity is closely correlated with $9 \mathrm{~KB}$ (human nasopharyngeal carcinoma) cytotoxicity $(\mathrm{p}=0.036$ and kappa $=0.56) . \mathrm{ED}_{50}$ values for cytotoxicities are generally about one-tenth the $\mathrm{LC}_{50}$ values found in the brine shrimp test. Thus, it is possible to detect and then monitor the fractionation of cytotoxic, as well as 3PS (P388) (in vivo murine leukaemia) active extracts using the brine shrimp lethality bioassay ${ }^{[11]}$.

\section{Results and Discussion of the Test Samples of $S$. jambos}

Bioactive compounds are almost always toxic at higher dose. Thus, in vivo lethality in a simple zoological organism can be used as a convenient informant for screening and fractionation in the discovery of new bioactive natural products.

\subsection{Chemical Investigation of the Purified Crude Extract of S. Jambos}

One steroid and two triterpenes were yielded from the methanolic extracts of stem barks of $S$. jambos. Through repeated chromatography and purification, extensive spectroscopic technique (proton NMR techniques) was applied to determine the structure.

\subsubsection{Characterization of SJ-61 as Friedelin}

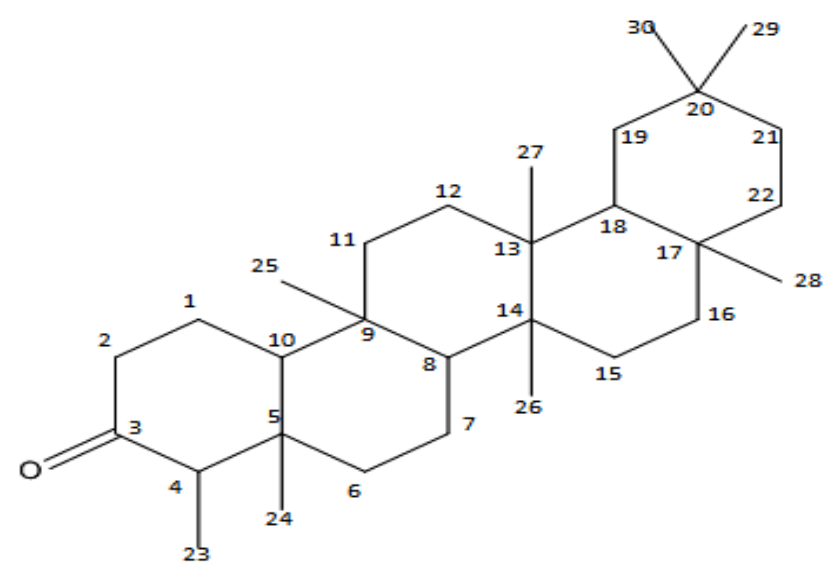

Figure 1. Compound SJ-61 (Friedelin)

Compound SJ-61 was obtained (Fig-1) from the VLC fraction 6 (15\% ethyl acetate in hexane) of crude extract as white crystals. It was evident as a yellow spot on TLC (Silica gel $\mathrm{PF}_{254}$ ) when the developed plate was sprayed with vanillin-sulfuric acid followed by heating at $110^{\circ} \mathrm{C}$ for $5-10$ minutes. It was found to be soluble in petroleum ether, hexane, ethyl acetate and chloroform.

The ${ }^{1} \mathrm{H}$ NMR spectrum $\left(500 \mathrm{MHz}, \mathrm{CDCl}_{3}\right)$ of SJ-61 (Figure-2 \& table-1) revealed signal for two double doublet of proton intensity at $\delta 2.23$ typical for $\mathrm{H}-2 \mathrm{~b}$ and at $\delta 2.23$ typical for $\mathrm{H}-1 \mathrm{a}(1 \mathrm{H}$, dd $\mathrm{J}=13.0,7.5 \mathrm{~Hz})$. A one proton multiplet was found for $\mathrm{H}-4$ of pentacyclic triterpenoid and one equatorial proton $\left(\mathrm{H}_{\mathrm{eq}}-2\right)$ at $\delta$ 2.37. The spectrum displayed another multiplate at $\delta 1.96$ for $\mathrm{H}-1 \mathrm{a}$, originated from eight singlet signals in the regions $0.71 \mathrm{ppm}, 0.86 \mathrm{ppm}$, $0.87 \mathrm{ppm}, 0.94 \mathrm{ppm}, 0.99 \mathrm{ppm}, 1.00 \mathrm{ppm}, 1.04 \mathrm{ppm}$ and 1.17 ppm each integrating for three protons assignable to eight tertiary methyl groups at C-24, C-25, C-23, C-30, C-26, C-27, C-28 and C-29 respectively. 
Table 1. Comparison between ${ }^{1} \mathrm{H}$ NMR spectral data of SJ-61(500 MHz) and Friedelin in CDCl (Dhaka Univ. J. Sci. 59(2): 179-180, 2011 (July).

\begin{tabular}{lll}
\hline \multirow{2}{*}{ Protons } & $\delta_{\mathrm{H}}$ in $\mathbf{~ p p m ~ i n ~} \mathbf{C D C l}_{\mathbf{3}}$ & \\
\cline { 2 - 3 } & $\mathbf{S J}-\mathbf{1} \mathbf{F}$ & Friedelin \\
\hline $\mathrm{H}-1 \mathrm{a}$ & $1.96(1 \mathrm{H}, \mathrm{m})$ & $1.97(1 \mathrm{H}, \mathrm{m})$ \\
$\mathrm{H}-2 \mathrm{~b}$ & $2.29(1 \mathrm{H}, \mathrm{dd}, 13.0,7.5 \mathrm{~Hz})$ & $2.28(1 \mathrm{H} \mathrm{dd} 13.2,7.2 \mathrm{~Hz})$ \\
$\mathrm{H}-4$ & $2.37(1 \mathrm{H}, \mathrm{m})$ & $2.40(1 \mathrm{H}, \mathrm{m})$ \\
$\mathrm{H}_{3}-23$ & $0.87(3 \mathrm{H}, \mathrm{d} 7.5 \mathrm{~Hz})$ & $0.89(3 \mathrm{H}, \mathrm{d}, \mathrm{J}=7.2 \mathrm{~Hz})$ \\
$\mathrm{H}_{3}-24$ & $0.71(3 \mathrm{H}, \mathrm{s})$ & $0.74(3 \mathrm{H}, \mathrm{s})$ \\
$\mathrm{H}_{3}-25$ & $0.86(3 \mathrm{H}, \mathrm{s})$ & $0.88(3 \mathrm{H}, \mathrm{s})$ \\
$\mathrm{H}_{3}-26$ & $0.99(3 \mathrm{H}, \mathrm{s})$ & $1.01(3 \mathrm{H}, \mathrm{s})$ \\
$\mathrm{H}_{3}-27$ & $1.00(3 \mathrm{H}, \mathrm{s})$ & $1.02(3 \mathrm{H}, \mathrm{s})$ \\
$\mathrm{H}_{3}-28$ & $1.04(3 \mathrm{H}, \mathrm{s})$ & $1.06(3 \mathrm{H}, \mathrm{s})$ \\
$\mathrm{H}_{3}-29$ & $1.17(3 \mathrm{H}, \mathrm{s})$ & $1.19(3 \mathrm{H}, \mathrm{s})$ \\
\hline
\end{tabular}

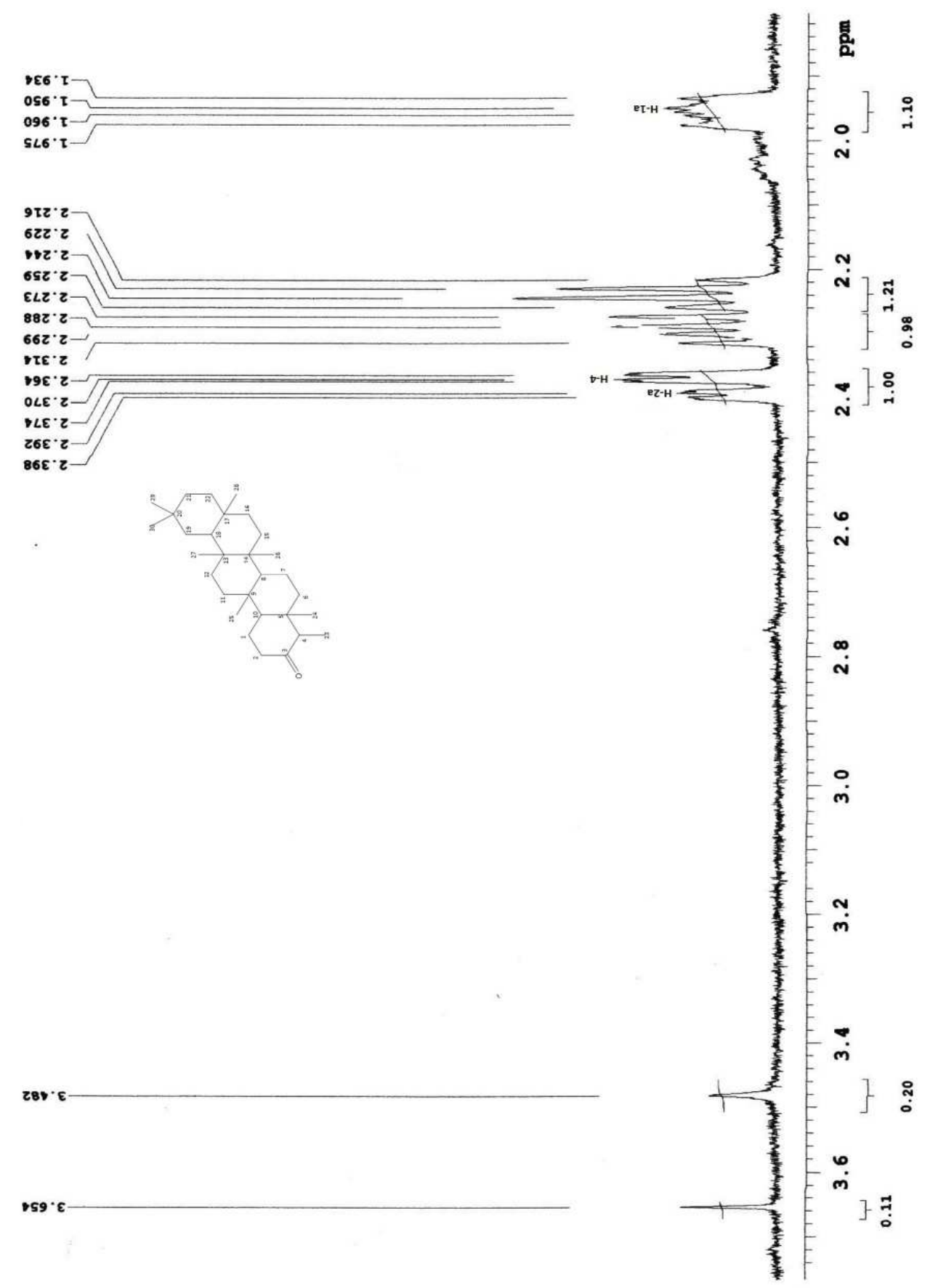

Figure 2. ${ }^{1} \mathrm{H} N \mathrm{NM}$ of spectrum of $\mathrm{SJ}-61$ in $\mathrm{CDCl}_{3}$ 
Table 2. ${ }^{1} \mathrm{H}$ NMR spectral data of SJ-92 (500 MHz) and B-sitosterol (Dhaka Univ. J. Sci. 59(2): 179-180, 2011 (July) in CDCl 3.

\begin{tabular}{lll}
\hline \multirow{2}{*}{ Position } & $\delta_{\mathbf{H}}$ in $\mathbf{~ p p m ~ i n ~} \mathbf{C D C l}_{\mathbf{3}}$ & \\
\cline { 2 - 3 } & $\mathbf{S J}-\mathbf{9 2}$ & $\boldsymbol{\beta}$-sitosterol \\
\hline $\mathrm{H}-3$ & $5.34(1 \mathrm{H} \mathrm{d}, \mathrm{J}=5.2 \mathrm{~Hz})$ & $5.33(1 \mathrm{H} \mathrm{d}, \mathrm{J}=7.0 \mathrm{~Hz})$ \\
$\mathrm{H}-6$ & $3.52(1 \mathrm{H}, \mathrm{m})$ & $3.51(1 \mathrm{H}, \mathrm{m})$ \\
$\mathrm{H}_{3}-18$ & $0.67(\mathrm{~s})$ & $0.67(\mathrm{~s})$ \\
$\mathrm{H}_{3}-19$ & $1.00(\mathrm{~s})$ & $1.00(\mathrm{~s})$ \\
$\mathrm{H}_{3}-21$ & $0.91(3 \mathrm{H} \mathrm{d}, \mathrm{J}=6.4 \mathrm{~Hz})$ & $0.92(3 \mathrm{H} \mathrm{d}, \mathrm{J}=6.6 \mathrm{~Hz})$ \\
$\mathrm{H}_{3}-26$ & $0.84(3 \mathrm{H} \mathrm{d}, \mathrm{J}=7.2 \mathrm{~Hz})$ & $0.84(3 \mathrm{H} \mathrm{d}, \mathrm{J}=7.0 \mathrm{~Hz})$ \\
$\mathrm{H}_{3}-27$ & $0.82(3 \mathrm{H} \mathrm{d}, \mathrm{J}=7.2 \mathrm{~Hz})$ & $0.81(3 \mathrm{H} \mathrm{d}, \mathrm{J}=7.0 \mathrm{~Hz})$ \\
$\mathrm{H}_{3}-29$ & $0.85(3 \mathrm{H} \mathrm{t}, \mathrm{J}=6.0 \mathrm{~Hz})$ & $0.85(3 \mathrm{H}, \mathrm{t}, \mathrm{J}=7.0 \mathrm{~Hz})$ \\
\hline
\end{tabular}

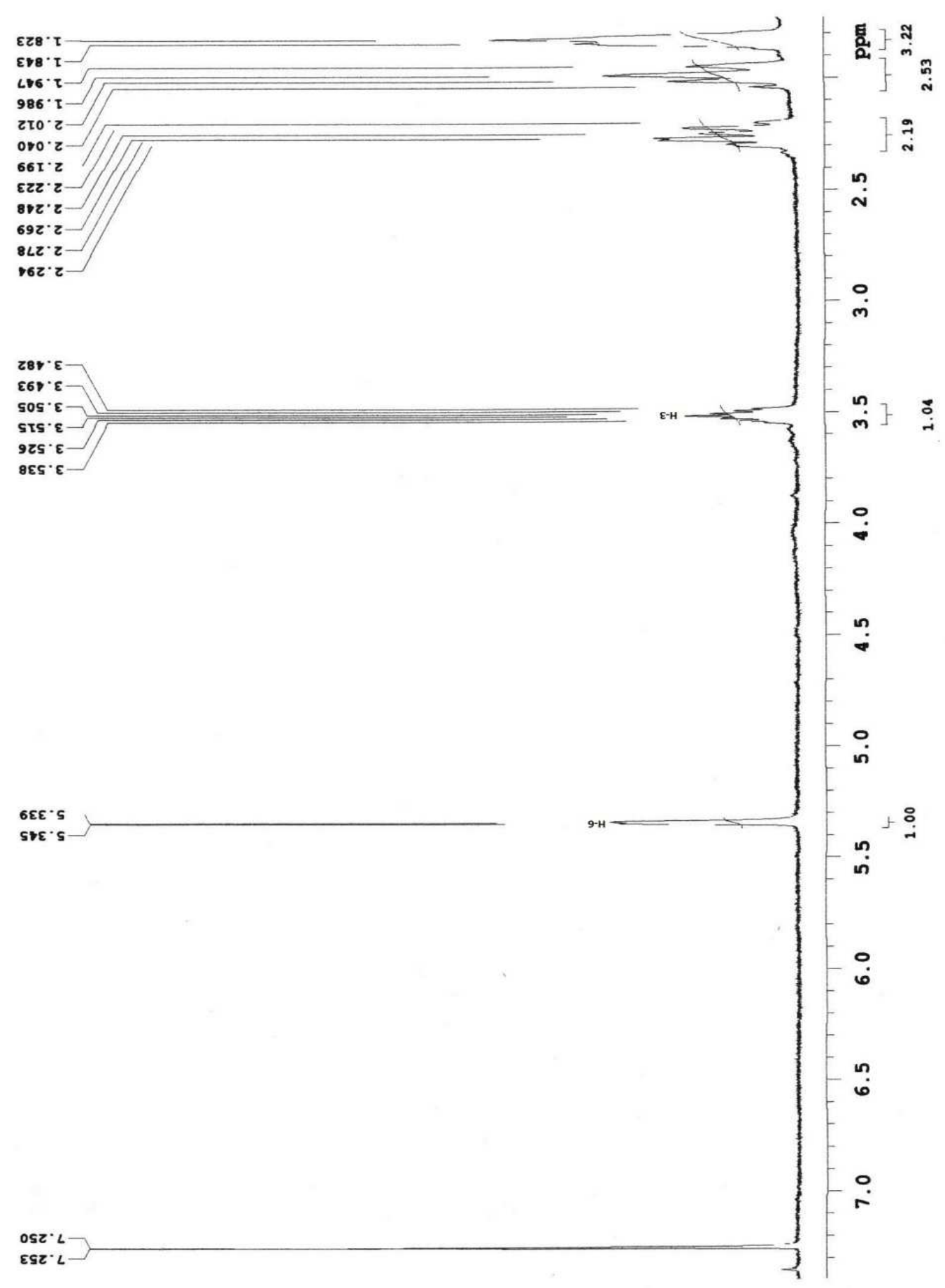

Figure 3. ${ }^{1} \mathrm{H} N \mathrm{NM}$ spectrum of SJ-92 in $\mathrm{CDCl}_{3}$ 


\subsubsection{Characterization of SJ-92 as $\beta$-Sitosterol}<smiles>CCC(C)C(CC)CCC(C)C1CCC2C3CC=C4CC(O)CCC4(C)C3CCC12C</smiles>

Figure 4. Compound SJ-92 ( $\beta$-Sitosterol)

Compound SJ-92was obtained as needle shaped crystals (Fig-4). It was evident as a purple spot on TLC (Silica gel $\mathrm{PF}_{254}$ ) when the developed plate was sprayed with vanillinsulfuric acid followed by heating at $110^{\circ} \mathrm{C}$ for $5-10$ minutes. It was found to be soluble in petroleum ether, hexane, ethyl acetate and chloroform.

The ${ }^{1} \mathrm{H}$ NMR spectrum $\left(500 \mathrm{MHz}, \mathrm{CDCl}_{3}\right)$ of SJ-92 (Figure-3 \& Table-2) revealed the typical signal for the olefinic $\mathrm{H}-3$ of the steroidal skeleton was evident from a doublet at $\delta 5.34$ integrating one proton. A one proton multiplet was found at $\delta 3.52$. The position and multiplicity of which was indicative of H-6 of the steroidal nucleus. The spectrum further revealed signals at $\delta 0.67$ and $\delta 1.00(3 \mathrm{H}$ each) assignable to two tertiary methyl groups at C-18 and C19, respectively. The ${ }^{1} \mathrm{H}$ NMR spectrum showed two doublets centered at $\delta 0.83(\mathrm{~J}=7.2 \mathrm{~Hz})$ and at $\delta 0.81(\mathrm{~J}=7.2$ $\mathrm{Hz}$ ) which could be attributed to two methyl groups at C-25. The doublet at $\delta 0.91(\mathrm{~J}=6.4 \mathrm{~Hz})$ was demonstrative of a methyl group at C-20. On the other hand, the triplet of threeproton intensity at $\delta 0.85$ could be assigned to the primary methyl group attached to $\mathrm{C}-28$.

The above spectral features (Table-3) are in close agreement to those observed for $\beta$-sitosterol (Dhaka Univ. J. Sci. 59(2): 179-180, 2011 (July). On this basis, the identity of SJ-92 was confirmed as $\beta$-sitosterol. The identity of SJ-92 was further confirmed by CO-TLC with authentic sample, previously isolated in Phytochemical Research Laboratory.

\subsubsection{Characterization of SJ-184 as 3-nor-2,4- Secofriedelan-4-oxo-2-oic Acid Derivative}<smiles>C=C(CC1C(O)CC(C)(C(=C)CC(=O)O)C2(C)CC(O)C3(C)C1CCC1(C(=O)O)C=CC(C)(C)CC132)C(=O)O</smiles>

Figure 5. Compound SJ-184 (3-nor-2,4-Secofriedelan-4-oxo-2-oic Acid Derivative)

Compound SJ-184 was obtained (Fig-5) from the VLC fraction 16 (20\% methanol in ethyl acetate) of crude extract as white crystals. It was evident as a purple spot on TLC (Silica gel PF254) when the developed plate was sprayed with vanillin-sulfuric acid followed by heating at $110^{\circ} \mathrm{C}$ for 5-10 minutes. It was found to be soluble in petroleum ether, hexane, ethyl acetate and chloroform.

The ${ }^{1} \mathrm{H}$ NMR spectrum $\left(500 \mathrm{MHz}, \mathrm{CDCl}_{3}\right)$ of $\mathrm{SJ}-184$ (Figure-6 \& table-3) revealed signal for multiplet of proton intensity at $\delta 2.27$ typical for H-1. Seven singlet signals at $2.16 \mathrm{ppm}, 0.73 \mathrm{ppm}, 0.80 \mathrm{ppm}, 0.89 \mathrm{ppm}, 0.98 \mathrm{ppm}, 1.23 \mathrm{ppm}$ and $0.94 \mathrm{ppm}$, integrating for three protons assignable to seven tertiary methyl groups at C-22, C-23, C-24, C-25, C-26, C-28 and C-29 respectively.

Three proton singlet in the more deshielded region $(\delta=2.16 \mathrm{ppm})$ for methyl group at C-22. This high chemical shift is due to the attachment to ketone group.

From this above spectral features it is assumed that the compound have seven methyl protons, one of which is attached to a ketone group. So, it is proposed that the compound SJ-184 may be 3-nor-2,3-secofriedelan derivative.

Table 3. 'H NMRspectral data of SJ-184 as 3-nor-2,3-secofriedelan derivative (proposed) (J. Agric. Food Chem. 2006, 54, 3566 3571)

\begin{tabular}{ll}
\hline Protons & Chemical shift \\
\hline H-1 & $2.27(1 \mathrm{H}, \mathrm{m})$ \\
$\mathrm{H}-22$ & $2.16(3 \mathrm{H}, \mathrm{s})$ \\
$\mathrm{H}-23$ & $0.73(3 \mathrm{H}, \mathrm{s})$ \\
$\mathrm{H}-24$ & $0.80(3 \mathrm{H}, \mathrm{s})$ \\
$\mathrm{H}-25$ & $0.89(3 \mathrm{H}, \mathrm{s})$ \\
$\mathrm{H}-26$ & $0.98(3 \mathrm{H}, \mathrm{s})$ \\
$\mathrm{H}-28$ & $1.23(3 \mathrm{H}, \mathrm{s})$ \\
$\mathrm{H}-29$ & $0.94(3 \mathrm{H}, \mathrm{s})$ \\
\hline
\end{tabular}




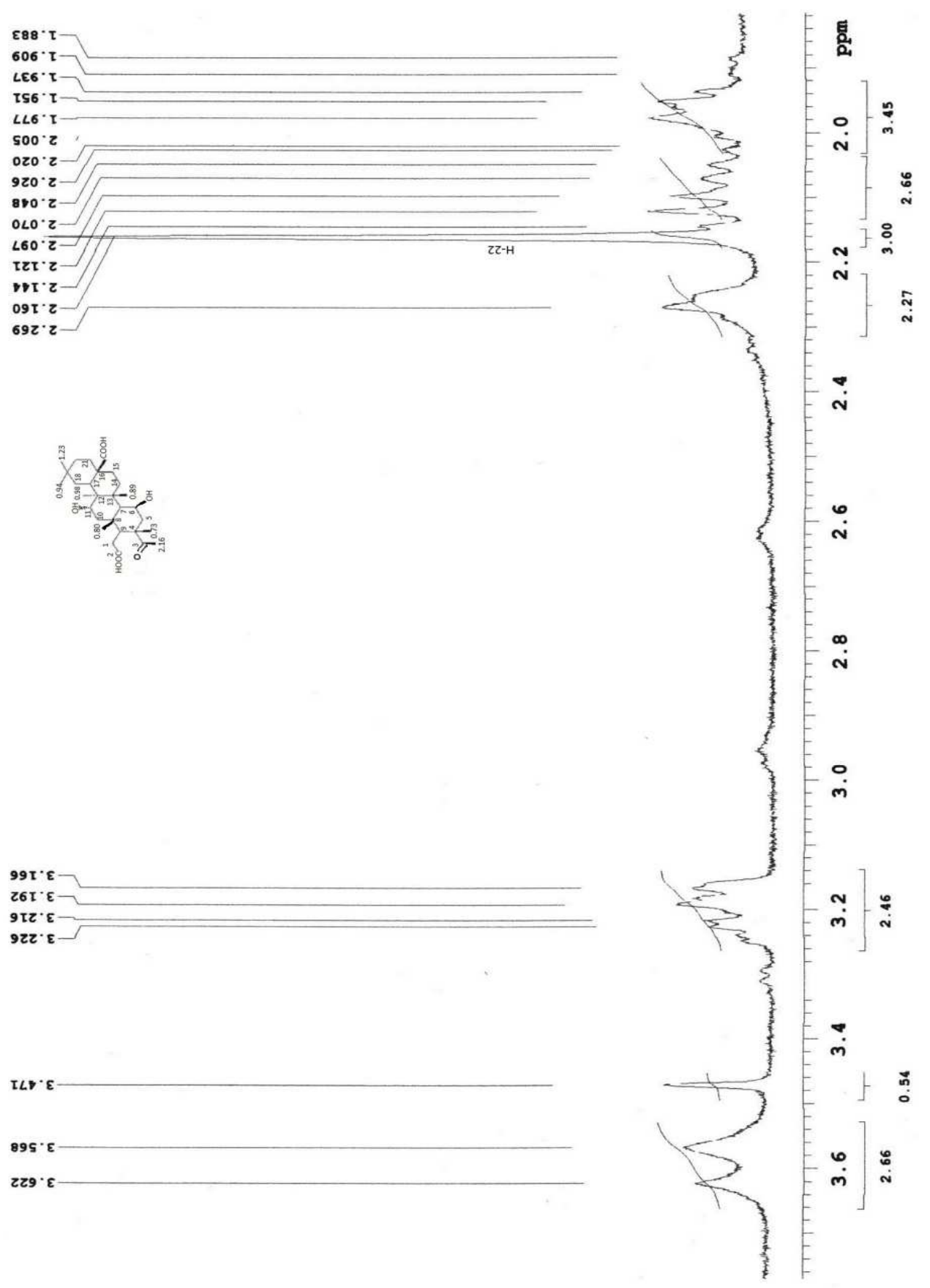

Figure 6. ${ }^{1} \mathrm{H} N \mathrm{NR}$ spectrum of $\mathrm{SJ}-184$ in $\mathrm{CDCl}_{3}$

\subsection{Brine Shrimp Lethality Assay o of the Purified Crude Extract of S. Jambos}

In the present bioactivity study all the crude extracts, hexane, carbon tetrachloride, chloroform and aqueous soluble fractions of methanolic extract showed positive results indicating that the test samples are biologically active. Each of the test samples showed different mortality rates at different concentrations. Plotting of $\log$ of concentration versus percent mortality for all test samples showed an approximate linear correlation. From the graphs, the median lethal concentration $\left(\mathrm{LC}_{50}\right.$, the concentration at which $50 \%$ mortality of brine shrimp nauplii occurred) was determined for the samples.

The methanolic extract of bark and the different partitionate of the methanolic extract i.e. hexane soluble partitionate (HSF), carbon tetrachloride soluble partitionate (CTCSF), chloroform soluble partitionate (CSF) and aqueous soluble partitionate (AQSF) of S.jambos were subjected to brine shrimp lethality bioassay following the procedure of Meyer et al., (1982). The lethality of the extractives to brine shrimp was determined and the results are given in Table-4.

The lethal concentration $\mathrm{LC}_{50}$ of the test samples after 24 hr. was obtained by a plot of percentage of the shrimps died 
against the logarithm of the sample concentration (toxicant concentration) and the best-fit line was obtained from the curve data by means of regression analysis.

Vincristine sulfate (VS) was used as positive control and the $\mathrm{LC}_{50}$ was found $0.451 \mu \mathrm{g} / \mathrm{ml}$ for VS. Compared with the negative control VS (positive control) gave significant mortality and the $\mathrm{LC}_{50}$ values of the different extractives were compared to this positive control.

The $\mathrm{LC}_{50}$ values of HSF, CTCSF, CLSF and MESSJ were found to be $257.596 \mu \mathrm{g} / \mathrm{ml}, 13.616 \mu \mathrm{g} / \mathrm{ml}, 64.943 \mu \mathrm{g} / \mathrm{ml}$, and $6.97 \mu \mathrm{g} / \mathrm{ml}$ respectively. MESF and CTCSF showed significant lethality whereas CLSF showed moderate activity and HSF showed least activity.

Table 4. $L C_{50}$ values of the test samples of S.jambos

\begin{tabular}{llll}
\hline Test samples & Regression line & $\mathbf{R}^{\mathbf{2}}$ & $\mathbf{L C}_{\mathbf{5 0}}(\boldsymbol{\mu} \mathbf{g} \mathbf{m} \mathbf{m})$ \\
\hline VS & $\mathrm{y}=30.799 \mathrm{x}+60.64$ & 97.29 & 0.451 \\
MESF & $\mathrm{y}=34.629 \mathrm{x}+20.803$ & 0.9497 & 6.97 \\
HSF & $\mathrm{y}=19.485 \mathrm{x}+3.3579$ & 0.972 & 247.596 \\
CTCSF & $\mathrm{y}=39.689 \mathrm{x}+4.9914$ & 0.9463 & 13.616 \\
CLSF & $\mathrm{y}=35.233 \mathrm{x}-14.95$ & 0.8681 & 69.734 \\
AQSF & $\mathrm{y}=35.233 \mathrm{x}+11.05$ & 0.982 & 12.75 \\
\hline
\end{tabular}

$\mathrm{VS}=$ Vincristine sulphate, $\mathrm{MESF}=$ Methanol soluble fraction, $\mathrm{HSF}=$ Hexane soluble fraction, $\mathrm{CTCSF}=$ Carbon tetrachloride soluble fraction, $\mathrm{CLSF}=$ Chloroform soluble fraction

\section{Conclusion}

Different partitionates of the methanolic extract of the stem bark of $S$. jambos were investigated for isolation of the potent secondary metabolites of this plant. Successive chromatographic separation and purification of the VLC partitionates of the crude methanolic extract yielded a total of three compounds. The structure of these compounds were elucidated as $\beta$-sitosterol, friedelin and 3-nor-2,3secofriedelan derivative (proposed).The chloroform soluble fraction and the carbon tetrachloride soluble fraction of the stem bark of $S$. jambos exhibited mild to moderate antimicrobial activity. Methanolic extract of stem barks and the chloroform soluble fraction of this plant showed significant free radical scavenging activity.

In addition, the crude methanolic extract of stem barks, the chloroform partitionate, and carbon tetrachloride of the crude extract of the plant gave better cytotoxic effect.

In conclusion, considering the potential bioactivity, this plant can be studied extensively to find out their unexplored efficacy and to rationalize their use as traditional medicine. Further investigation will lead to isolation, purification and characterization of new molecules from this plant.

\section{References}

[1] Farnsworth N.R., Akerele O., Bingel A.S., Soejarto D.D., Guo Z., 1985.Medicinal plants in therapy. Bull W H O 63: 965-981

[2] Kumar S., Kumar R., Khan A., 2011, Medicinal plant resources: manifestation and prospects of life- sustaining healthcare system, Cont. J. Biol. Sci., 4 (1): 19 - 29

[3] Hong-Fang J., Jue-Juan L., Hong-Yu Z., 2009, Natural products and drug discovery. Can thousands of years of ancient medical knowledge lead us to new and powerful drug combinations in the fight against cancer and dementia, EMBO Rep. Mar 2009; 10(3): 194-200
[4] Ayensu E.S., DeFilipps R. A., 1978, Endangered and Threatened Plants of the United States. Washington, DC: Smithsonian Institution

[5] Cronquist A., 1988, The Evolution and Classification of Flowering Plants, Bronx, NY:New York Botanical Garden

[6] Tippo O., Stern W. L., 1977, Humanistic Botany. New York:W.W. Norton

[7] Schultes R.E., 1972, The future of plants as sources of new biodynamic compounds: Plants in the Development of Modern Medicine (Swain T, ed). Cambridge, MA:Harvard University Press, 103-124

[8] Verpoorte R., 2000. Pharmacognosy in the new millennium: lead finding and biotechnology. J Pharm Pharmacol. 52, 253262.

[9] Burbaum J.J., Ohlmeyer M.H., Reader J.C., Henderson I, Dillard L.W., Li J., Randle T.L.,Sigal N.H., Chelsky D., Baldwin J.J., 1995, Proc Natl Acad Sci U S A, 92(13): 60276031

[10] Md. Reyad-Ul-Ferdous, Sayma Akhter, Md. Zahirul Islam Khan, Md. Eshak Khan, Md. Atiqul Islam, Md. Sharif Ullah. Ex-Vivo Anti-Inflammatory and Antimicrobial Activities of the Leaves of Bauhinia acuminata. American Journal of Life Sciences. Vol. 2, No. 5, 2014, pp. 267-270. doi:10.11648/j.ajls.20140205.13

[11] Reyad-ul-Ferdous M, Alam TT, Islam MA, Khan MZI, Tasnim F, et al (2014) Ex-Vivo Cardioprotective and Cytotoxic Screening of Fruits of Parmentiera ereifera Seem. Biol Med 6: 219. doi: $10.4172 / 0974-8369.1000219$

[12] Van Wagenen B.C., Larsen R., Cardellina J.H. II, Ran dazzo D., Lidert Z.C., Swithenbank C., 1993. Ulosantoin, a potent insecticide from the sponge Ulosa ruetzleri. J. Org. Chem. 58, 335-337

[13] Meyer B.N., Ferringni N.R., Puam, J.E., Lacobsen L.B., Nichols D.E., 1982. Drug Info Journal, 31, 516-554

[14] Maclaughlin J. L., Anderson J. E., Rogers and Lingling, L., 1998, Drug Info Journal, 32: 513-524 